Research Article

\title{
The Influence of an Expansive Agent on the Performance of Cement-Stabilized Coral Sand
}

\author{
Jiuguang Geng, ${ }^{1}$ Mingyuan Chen $\left(D,{ }^{1}\right.$ Tao Shang, ${ }^{1}$ Cheng Xue, ${ }^{2}$ Huaxin Chen, ${ }^{1}$ \\ and Chao Zhang ${ }^{1}$ \\ ${ }^{1}$ School of Materials Science and Engineering, Chang'an University, Xi'an, China \\ ${ }^{2}$ CCCC Second Highway Engineering Co Ltd., Xi'an, China \\ Correspondence should be addressed to Mingyuan Chen; chenmy@chd.edu.cn
}

Received 12 May 2020; Revised 21 December 2020; Accepted 22 December 2020; Published 8 January 2021

Academic Editor: Valeria Vignali

Copyright ( 2021 Jiuguang Geng et al. This is an open access article distributed under the Creative Commons Attribution License, which permits unrestricted use, distribution, and reproduction in any medium, provided the original work is properly cited.

Using coral sand as an aggregate to build the base layer of pavement on islands and along coasts in China has the potential to not only reduce construction costs and time but also lessen carbon emissions during transportation. Due to coral sand's fragility, porosity, and high water absorption, the amount of cement is higher than that of ordinary cement-stabilized gravel, which leads to the high strength but easy cracking of the base layer. The expansion agent is added to improve the shrinkage characteristics of cement-stabilized coral sand. To ensure the validity of our results, the mixing ratio of cement-stabilized coral sand was optimized according to its characteristics, and the effects of the cement content, the expansion agent type, and dosage on coral sand's mechanical properties, dry shrinkage, and antiscour performance of cement-stabilized coral sand were studied using an orthogonal test. The results indicate that cement content is one of the most important factors affecting compressive strength, scouring, and dry shrinkage. The optimal mix ratio of cement-stabilized coral sand is $6 \%$ cement to $8 \%$ CAS expansion agent (accounting for cement), which is sufficient to meet the design criteria for heavy-duty traffic subbases.

\section{Introduction}

Infrastructure construction on islands and along coasts is necessary for transportation and to access marine resources. Gravel materials such as aggregates and sand used for road construction are scarce, and thus they must be imported, which adds to construction time and cost. More seriously, the exploitation of aggregate and sand causes environmental damage, and carbon emissions increase because of the longdistance transportation of building materials. Coral sand, however, is abundant on the islands and can be used to fill the pavement base layer [1-3]. However, coral sand material is brittle and porous and has a high water absorption rate $[4,5]$. The main component of coral sand is carbonate, which has a calcium content of up to $98 \%$ and contains skeletal debris from wormholes, echinoderms, and other marine life [6]. Due to the particularity of coral sand, its physical and mechanical properties have been extensively studied $[7,8]$. Bryant [9] found in his calcium soil test that the greater the carbonate content, the greater the compression index. The reason for the breakage of calcareous sand is the plastic deformation during compression, which is the main reason for the decreased strength of calcareous soil [10]. With the in-depth study of the composition and properties of coral sand concrete, it is defined as lightweight aggregate concrete, which has a lower density than ordinary concrete and has early strength properties [11]. King's related mechanical tests [12] were carried out on the base layer of coral sand piles, and the pull-out resistance was in the range of 5-19 kPa. Therefore, according to the characteristics of the coral sand project, the cement-stabilized coral sand mix design and road performance research were carried out to protect the ecological environment and reduce project costs, which offer significant social and economic benefits.

Problems with pavement, such as cracking of the base layer and insufficient strength, are prevalent in road construction and maintenance [13]. Cement materials are commonly prone to cracking. The mechanism of crack 
generation and the development of control methods are popular research topics for road engineering scholars. George [14] discussed the factors affecting the shrinkage of cement-stabilized soil. Under the same conditions, the higher the clay content in the soil, the stronger the shrinkage ability of the cement-stabilized soil. Sheng [15] applied the grey system theory to establish a grey prediction model depicting the influencing factors of aggregate fractal dimension, strength, and moisture content of a mixture, and Sylovanyuk et al. [16] proposed the fracture toughness $\left(\mathrm{K}_{\mathrm{IC}}\right)$ for predicting the crack resistance of fiber composites based on cement matrix production. The use of steel slag as an aggregate and the use of lime fly ash as a binder to prepare the base material [17] or the addition of steel fiber and rubber or other admixtures [18] can improve the splitting strength and shrinkage of cement-stabilized materials. Gong et al. [19] used the crack resistance index to study the effect of cement fineness on the overall crack resistance of roller compacted concrete and found that the use of coarse cement is a measure to compensate for the low thermal crack resistance of RCC. Wu et al. [20] examined the expansion of a cement mortar mixed expansion agent under standard curing and film curing conditions and its compressive strength under restraint conditions, indicating that the compressive strength of the expander mortar was slightly higher than that of the base mortar. Zhang et al. [21] studied the mechanism of the expansion characteristics of the expanded cement slurry in the presence of different doses of a temperature-increasing inhibitor (TRI), and the optimum dosage was $0.4 \%$. An expansion agent can offset the tension stress caused by temperature lowing or dry shrinkage of materials, and thus it can improve the anticracking and imperviousness performance of concrete.

Coral sand often requires high cement usage and water consumption to meet strength requirements. However, the high amount of cement easily generates shrinkage cracks. The addition of expansion agents to cement to avoid the shrinkage cracks of cement-based materials is the most common method, but the variety and amount of expansion agents are unknown. Therefore, the most important factors affecting shrinkage characteristics of cement-stabilized coral sand mixture are determined by orthogonal tests in this study. The road performance was evaluated through mechanical properties and antiscouring performance. Then, the optimal mix ratio was determined to suit the design criteria of the base construction.

\section{Materials and Methods}

2.1. Coral Sand. The coral sand required for the trial was taken from Malaysia. The screening results and basic performance of the coral sand are shown in Tables 1 and 2 .

2.2. Cement. The cement used in the study was P.O 42.5 cement (according to JTG/T F20 (2015)-3.2) [22]. Its chemical composition and physical properties are shown in Tables 3 and 4, respectively.

2.3. Expansion Agent. Cement-stabilized coral sand has the problem of shrinkage cracking, so expansion agents were used to resist shrinkage. The selected expansion agents were FQY-II, UEA, and a calcium sulphoaluminate expansion agent (CAS). FQY-II, produced by Hefei Sanyuan Special Building Materials Factory, is composed of white granular crystals and is a double expansion source of calcium oxide and calcium sulphoaluminate. UEA is produced by Shanghai Tongtai Concrete Admixture Co., Ltd., and causes the concrete to expand moderately in the early and middle stages, mainly using anhydrous aluminum sulfate and alum as the expansion source. The main components of CAS are calcium aluminate clinker, gypsum, and alum. It is produced by Beijing Dechang Weiye Construction Engineering Technology Co., Ltd., and mixed with cement and water to form ettringite by hydration reaction.

2.4. Orthogonal Design. The heavy-duty compaction test was performed according to T0804 method in JTG E51-2009 [23]. The concentration cement used in the tests was $6 \%, 7 \%$, and $8 \%$ (mass), and five different water contents were selected to perform a compaction test. After mixing, the mixture was placed in a compaction cylinder, and then the electric compactor was used to perform compaction in five layers. Each layer was hammered 27 times according to the industry standard. After the compaction test, the optimum moisture content and maximum dry density for different cement contents were obtained, as shown in Table 5. Then, the coral sand was mixed with cement and an expansion agent before adding water to bring the mixture to the desired water content. The materials were moved into the molds $(\phi 100 \mathrm{~mm} \times 100 \mathrm{~mm}$ and $100 \mathrm{~mm} \times 100 \mathrm{~mm} \times 400 \mathrm{~mm})$ in order to prepare stabilized test samples. After formed, the specimens were cured in a moist room (temperature $20 \pm 1^{\circ} \mathrm{C}$, and $\left.\mathrm{RH} 95 \%\right)$.

Orthogonal experiment is usually used to research multifactorial effects on test indices. There are many factors that can affect properties of cement-stabilized coral sand. In order to obtain the desired mechanical properties, low shrinkage rate, and low scouring rate, orthogonal experiments were adopted to optimize the mix proportion. Here, the cement content $(\mathrm{A})$, the expander type (B), and the expander content (C) are used as the experimental factors, and the level is set to 3 . The compressive strength, scour rate, and average dry shrinkage factor at the age of 28 days were set as the assessment indices. The orthogonal design of the experiment is shown in Table 6 .

2.5. Unconfined Compressive Strength Test. The unconfined compressive strength of specimens was tested using a microcomputer control electronic universal testing machine (CMT5105) and referred to a standard for inorganic binder stabilized material test method (JTG/T 0805). The loading rate is $1 \mathrm{~mm} / \mathrm{min}$. After each specimen was damaged, the 
TABLE 1: Screening results of coral sand.

\begin{tabular}{lcccccccc}
\hline Sieve size $(\mathrm{mm})$ & 9.5 & 4.75 & 2.36 & 1.18 & 0.6 & 0.3 & 0.15 & 0.075 \\
\hline Through rate $(\%)$ & 100 & 93.9 & 87.3 & 71.3 & 53.8 & 27.3 & 10.5 & 0.03 \\
\hline
\end{tabular}

TABLE 2: Basic performance of coral sand.

\begin{tabular}{lccccc}
\hline Apparent density $\left(\mathrm{g} / \mathrm{cm}^{3}\right)$ & Bulk density $\left(\mathrm{g} / \mathrm{cm}^{3}\right)$ & Water absorption (\%) & Sand equivalent (\%) & Rugged (\%) & Methylene blue value \\
\hline 2.626 & 1.287 & 15.8 & 71.8 & 2.37 & 1.25 \\
\hline
\end{tabular}

Table 3: Chemical analysis of the cement (wt\%).

\begin{tabular}{lcccccccc}
\hline Components & $\mathrm{SiO}_{2}$ & $\mathrm{Al}_{2} \mathrm{O}_{3}$ & $\mathrm{CaO}$ & $\mathrm{Fe}_{2} \mathrm{O}_{3}$ & $\mathrm{MgO}$ & $\mathrm{K}_{2} \mathrm{O}$ & $\mathrm{Na}_{2} \mathrm{O}$ & $\mathrm{SO}_{3}$ \\
\hline Cement & 22.61 & 5.94 & 63.72 & 3.22 & 1.98 & 0.39 & 0.12 & 1.99 \\
\hline
\end{tabular}

TABle 4: Physical properties of the cement.

\begin{tabular}{lcccr}
\hline Setting time $(\mathrm{min})$ & \multicolumn{2}{c}{ Flexural strength (MPa) } & \multicolumn{2}{c}{ Compressive strength (MPa) } \\
Initial & Final & $7 \mathrm{~d}$ & $28 \mathrm{~d}$ & $7 \mathrm{~d}$ \\
\hline 92 & 220 & 4.7 & 8.9 & 33.7 \\
\hline
\end{tabular}

TABLE 5: The optimum water content and the maximum dry density.

\begin{tabular}{lcc}
\hline Cement content (\%) & The optimum water content $(\%)$ & The maximum dry density $\left(\mathrm{g} / \mathrm{cm}^{3}\right)$ \\
\hline 6.0 & 10.4 & 1.698 \\
7.0 & 10.7 & 1.712 \\
8.0 & 11.2 & 1.729 \\
\hline
\end{tabular}

TABLE 6: Orthogonal design of experiment.

\begin{tabular}{lccc}
\hline No. & Cement content (\%) & Expansion agent type & Expansion agent content (\%) \\
\hline CS-1 & $6(1)$ & FQY-II (1) & $4(1)$ \\
CS-2 & $7(2)$ & UEA (2) & $8(2)$ \\
CS-3 & $8(3)$ & CAS (3) & $12(3)$ \\
CS-4 & $6(1)$ & UEA (2) & $12(3)$ \\
CS-5 & $7(2)$ & CAS (3) & $4(1)$ \\
CS-6 & $8(3)$ & FQY-II (1) & $8(2)$ \\
CS-7 & $6(1)$ & CAS (3) & $8(2)$ \\
CS-8 & $7(2)$ & FQY-II (1) & $12(3)$ \\
CS-9 & $8(3)$ & UEA (2) & $4(1)$ \\
\hline
\end{tabular}

failure strength (F) was recorded. Six samples were investigated for each age and then averaged with the coefficient of variation $\leq 6 \%$. The unconfined compressive strength $\left(C_{28}\right.$ C28C28) was calculated using the following equation:

$$
C_{28}=\frac{F}{S}
$$

where $S$ is the compressive contact area of the specimen.

2.6. Dry Shrinkage Test. Dry shrinkage tests were carried out according to JC/T 70-2009. The first measurement was taken after 7 days of mixing, while the rest of the measurements were taken every 7 days for a total of 28 days. After 7 days of curing, the surface of the specimens was watered and wiped dry with a damp towel, and the initial length was measured. The shrinkage test was carried out for each of the four types of specimens; two tests assessed the change in water content using an electronic scale, and the other test evaluated the amount of deformation using dial gauges. The specimens of $100 \mathrm{~mm} \times 100 \mathrm{~mm} \times 400 \mathrm{~mm}$ were placed on the selfdesigned platform (Figure 1, patent number: 201820569760.8 ) in a shrinkage chamber at $20 \pm 1^{\circ} \mathrm{C}$ and $60 \pm 5 \% \mathrm{RH}$. In order to reduce any measurement errors, thick glass sheets were attached to both ends of the specimens. During the first 7 days, the data were read and each specimen was weighed daily. Then, the data were read every other day until the end of the 28 days. The test process is shown in Figure 2. The calculation formulas for dry shrinkage are demonstrated in equations (2)-(6): 


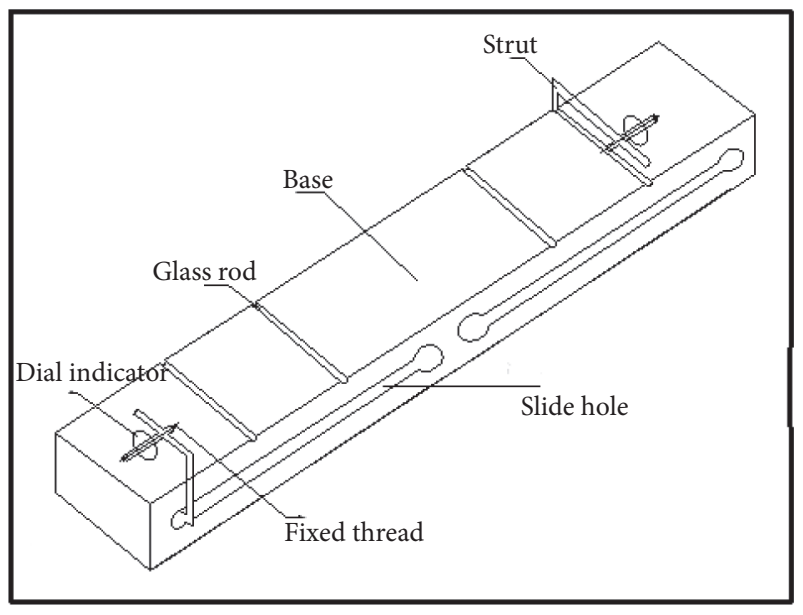

Figure 1: The self-designed platform.

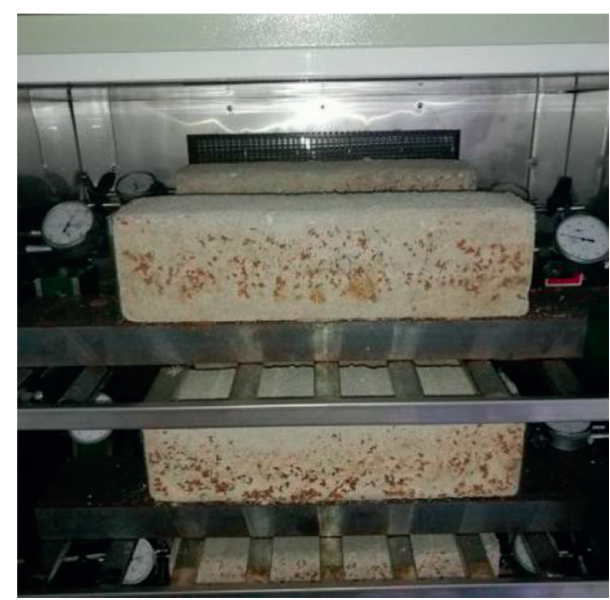

FIgURE 2: Dry shrink chamber.

$$
\begin{aligned}
\omega_{i} & =\frac{\left(m_{i}-m_{i+1}\right)}{m_{p}} \\
\delta_{i} & =\frac{\left(\sum_{j=1}^{4} X_{i, j}-\sum_{j=1}^{4} X_{i+1, j}\right)}{2}, \\
\varepsilon_{i} & =\frac{\delta_{i}}{L} \\
\alpha_{d i} & =\frac{\varepsilon_{i}}{\omega_{i}} \\
\beta_{d} & =\frac{\alpha_{d}}{d}, \\
& =\frac{\sum \varepsilon_{i}}{\left(d \times \sum \omega_{i}\right)}
\end{aligned}
$$

where $\omega_{i}$ is water loss rate (\%); $m_{i}$ is specimen quality $(\mathrm{g}) ; \delta_{i}$ is shrinkage amount $(\mathrm{mm}) ; \varepsilon_{i}$ is shrinkage strain $(\%) ; \alpha_{d i}$ is the shrinkage coefficient; $\beta_{d}$ is the average dry shrinkage coefficient; $X_{i, j}$ is dial gauge reading $(\mathrm{mm}) ; L$ is initial length of specimen; $i$ is number of days; and $j$ is the number of dial gauges.

2.7. Scour Test. A scour test was executed, applying the following steps. First, the samples were fixed in the scouring bucket with a clamp. Clean water was added to the bucket until the water surface reached $50 \mathrm{~mm}$ above the top surface of the scouring grid. The scouring cover was then secured. The impact force was set to $0.5 \mathrm{MPa}$, and the scouring frequency was set to $10 \mathrm{~Hz}$. The specimen was prescoured for 3 minutes. After the scouring was finished, the water outlet valve was opened and discharged, and the barrel was cleaned from residue. Then, water was added to the steel drum for the second time, and the scouring continued for 15 minutes. After the end, the sediment was dried, and the drying quality was recorded. The scour test was repeated 3 times. The calculation formula for the scour rate per unit time was as follows:

$$
P_{k}=\frac{\left(M_{k}-M_{0}\right)}{t_{k}} \text {, }
$$

where $P$ is the scour rate; $M$ is quality before and after scouring; $t$ is scouring time; and $k$ is $0 \mathrm{~min}, 3 \mathrm{~min}, 15 \mathrm{~min}$, $30 \mathrm{~min}$, and $45 \mathrm{~min}$.

\section{Results and Discussion}

3.1. The Results of Orthogonal Design. Results from the performance test of 9 groups of cement-stabilized coral sand are listed in Table 6, and the test results are shown in Tables 7 and 8.

As shown in Table 8 and Figure 3, $R$ of cement content on the average dry shrinkage coefficient is the max. This means that cement content is the most important factor that influences the cement-stabilized coral sand. Expansion agent content is the second most important factor, and expansion agent type is the third most important factor. To determine the unconfined compressive strength, the weight is consistent with the average dry shrinkage coefficient. For scouring, cement content and expansion agent type are the most important factors, and their effect on scouring is more obvious than that of the expansion agent content.

3.2. Dry Shrinkage. The shrinkage performance of cementstabilized coral sand directly affects the long-term performance of the pavement. The addition of an expansion agent can inhibit the shrinkage rate of the mixture. The main causes of shrinkage of cement materials are capillary tension caused by water evaporation, adsorption of water, and interaction between layers of gel. The dry shrinkage of cementstabilized coral sand specimens under 9 schemes was tested to obtain the corresponding dry shrinkage coefficient and water loss rate. These results are shown in Figures 4-6.

The shrinkage coefficient describes the shrinkage strain sensitivity of the materials to the water loss rate. Figure 4 depicts that the shrinkage coefficient of each group of cement-stabilized coral sand increased first with time and then decreased slightly before continuing to increase after 7 
TABLE 7: Orthogonal design and the results of experiment.

\begin{tabular}{lrcr}
\hline Number & $\beta_{28}\left(\times 10^{-7}\right)$ & $\mathrm{C}_{28}(\mathrm{MPa})$ & $P_{45}(\mathrm{~g} / \mathrm{min})$ \\
\hline CS-1 & 132.8 & 2.92 & 1.43 \\
CS-2 & 126.2 & 3.55 & 1.16 \\
CS-3 & 134.5 & 4.34 & 0.79 \\
CS-4 & 108.3 & 3.16 & 1.57 \\
CS-5 & 130.3 & 3.36 & 1.31 \\
CS-6 & 145.2 & 4.08 & 1.07 \\
CS-7 & 110.5 & 3.13 & 1.36 \\
CS-8 & 133.5 & 3.57 & 1.42 \\
CS-9 & 155.7 & 3.98 & 0.93 \\
\hline
\end{tabular}

TABLE 8: Results of range analysis.

\begin{tabular}{lcccccccc}
\hline Parameter & \multicolumn{3}{c}{$\beta_{28}$} & & & $\mathrm{C}_{28}$ & & \multicolumn{2}{c}{$P_{45}$} \\
& $\mathrm{~A}$ & $\mathrm{~B}$ & $\mathrm{C}$ & $\mathrm{A}$ & $\mathrm{B}$ & $\mathrm{C}$ & $\mathrm{A}$ & $\mathrm{C}$ \\
\hline $\mathrm{K}_{1}$ & 350.0 & 410.0 & 417.0 & 9.21 & 10.57 & 10.26 & 4.36 & 3.92 \\
$\mathrm{~K}_{2}$ & 389.0 & 389.0 & 381.0 & 10.48 & 10.69 & 10.76 & 3.89 & 3.66 \\
$\mathrm{~K}_{3}$ & 434.0 & 374.0 & 375.0 & 12.40 & 10.83 & 11.07 & 2.79 & 3.46 \\
$k_{1}$ & 116.7 & 136.7 & 139.0 & 3.07 & 3.52 & 3.42 & 1.45 & 1.31 \\
$k_{2}$ & 129.7 & 129.7 & 127.0 & 3.49 & 3.56 & 3.59 & 1.30 & 1.22 \\
$k_{3}$ & 144.7 & 124.7 & 125.0 & 4.13 & 3.61 & 3.69 & 0.93 & 1.15 \\
$\mathrm{R}$ & 28.0 & 12.0 & 14.0 & 1.06 & 0.09 & 0.27 & 0.52 & 0.15 \\
\hline
\end{tabular}

Note. A-cement content; B-expansion agent type; C-expansion agent content; $\beta_{28}$-average dry shrinkage coefficient in $28 \mathrm{days}$; C28-28 d unconfined compressive strength; $P_{45}-$ scour rate in 45 minutes.

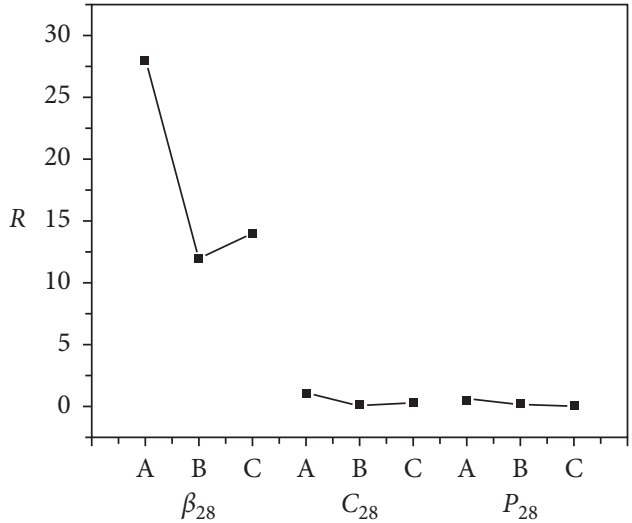

Figure 3: Results of range analysis.

days. The reason for this phenomenon was that the mixture loses water quickly in the initial 2 days, and the corresponding drying shrinkage coefficient increases sharply, showing that the mixture is more sensitive to the water loss rate. Then, due to the slower water loss rate, the internal self-shrinkage stress of the mixture decreases. At this time, the force generated by the expansion agent can compensate for the capillary tension, adsorbed water, and intermolecular force caused by the water shrinkage of the cementstabilized coral sand, thereby reducing the volume shrinkage caused by the shrinkage stress of the mixture. In addition, the hydration product of the expansion agent changes the microstructure by filling and refining the internal pore diameter of the mixture and reducing the porosity, thus improving the compactness of the cement-

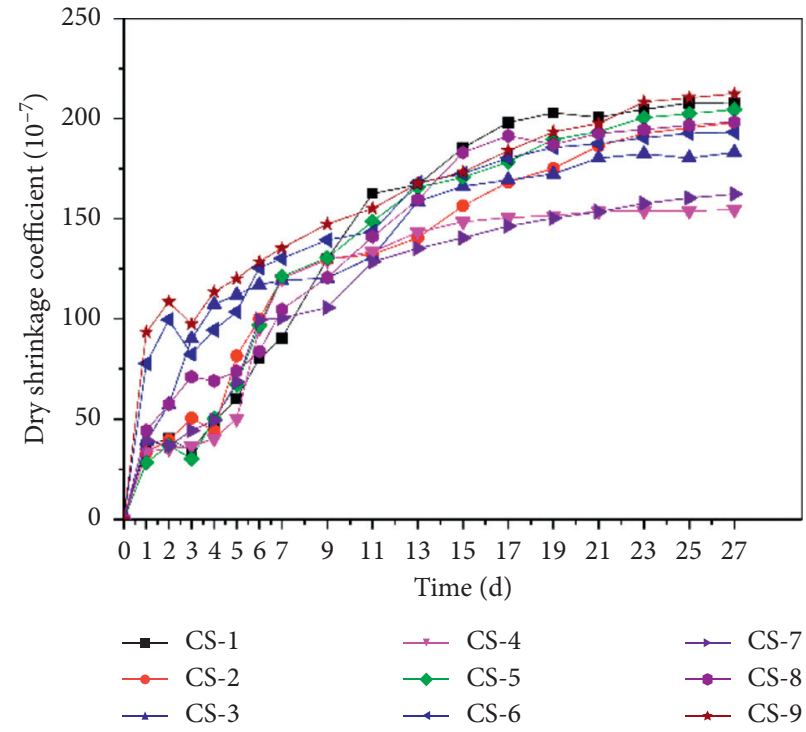

Figure 4: The law of dry shrinkage coefficient with time.

stabilized coral sand, so the cumulative dry shrinkage coefficient is slightly reduced. Then, with the continuous consumption of the expansion agent, the expansion force is not enough to compensate for the shrinkage stress, and thus the cumulative dry shrinkage coefficient of the cement-stabilized coral sand gradually increases.

In Figure 5, as time passed, the water loss rate of cementstabilized coral sand gradually increased, and after 15 days, it tended to stabilize. The water loss rate (about 14.9\%) was mainly concentrated before 7 days as well as $15.6 \%$ at 27 


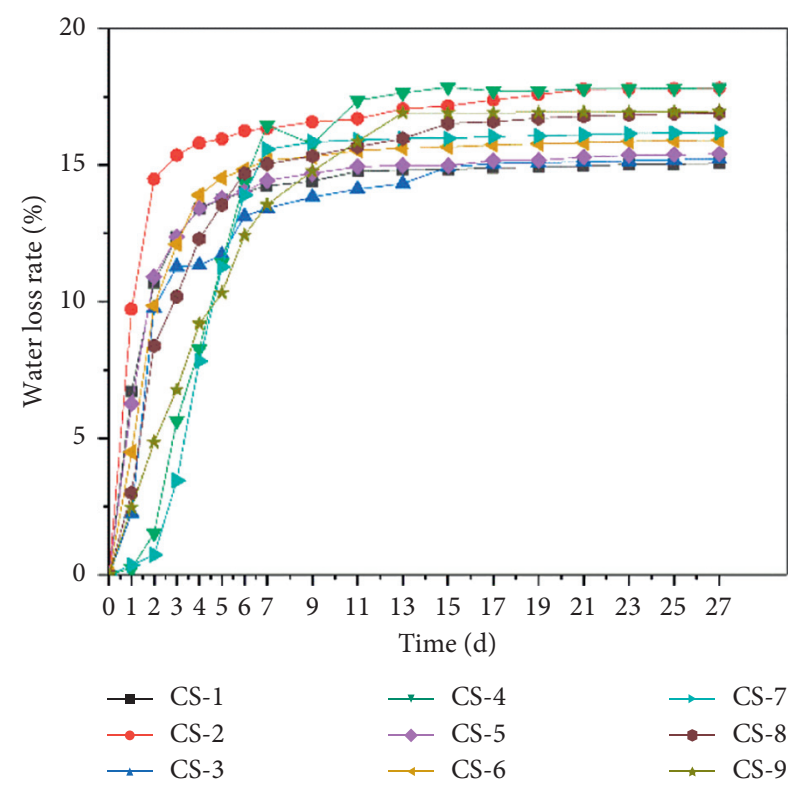

FIgURE 5: The changes of water loss rate with time.

days. The former accounted for $91.1 \%$ of the latter. The strength of cement-stabilized coral sand formed in the early stage of curing is not enough to offset the shrinkage stress caused by water loss. Therefore, in actual engineering, special attention should be paid to the maintenance water, thereby reducing the shrinkage effect at the initial stage of curing.

Figure 6 demonstrates that as the water loss rate increased, the shrinkage coefficient of cement-stabilized coral sand increased gradually. When the water loss rate was more than $14 \%$, the dry shrinkage coefficient increased rapidly, and the water loss rate of cement-stabilized coral sand went up to $17.8 \%$. Under the same water loss rate, the maximum dry shrinkage coefficient was $155.7 \times 10^{-7}$ (CS9 ), and the minimum was $126.2 \times 10^{-7}$ (CS-2).

The effect of the expansion agent content $\left(\mathrm{C}_{3}\right)$ on the dry shrinkage coefficient of Table 7 is $10.7 \%$ lower than that of $\mathrm{C}_{1}$ and only $2 \%$ lower than that of $\mathrm{C}_{2}$. This suggests that the proper amount of expansion agent leads to greater crack resistance because the amount of cement acting with the expansion agent is limited. Regarding the A, B, and C factors, the minimum $K_{i j}$ index is $K_{1 A}, K_{3 B}$, and $K_{3 C}$, respectively. Therefore, the optimal level combination of cement-stabilized coral sand with the average shrinkage coefficient as the evaluation standard is $\mathrm{A}_{1} \mathrm{~B}_{3} \mathrm{C}_{3}$.

3.3. Unconfined Compressive Strength (UCS). In practical engineering applications, it is possible to increase the amount of cement to make the mixture meet the design strength requirements. Although increasing the amount of cement can increase the strength of the mixture, it can also produce shrinkage cracks and affect road performance. The designed UCS of the cement-stabilized coral sand mixture in this study is $3-5 \mathrm{MPa}$. As can be seen from the analysis in Figure 7, the amount of expansion agent has a significant effect on the compressive strength, and

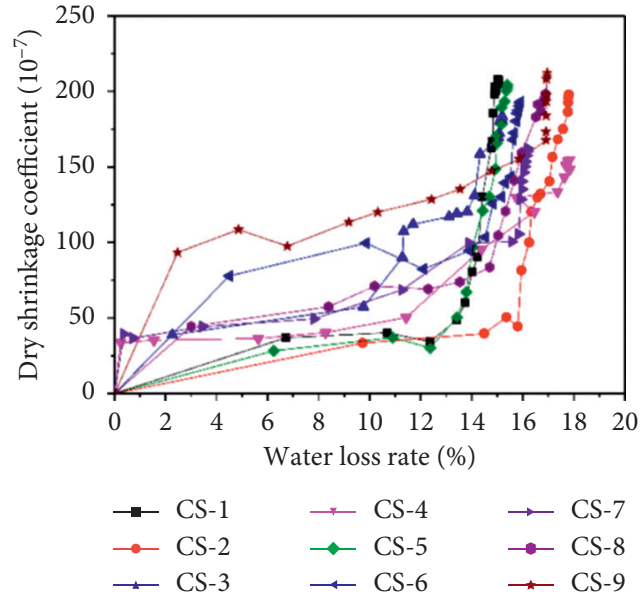

FIGURE 6: Relationship between dry shrinkage coefficient and water loss rate.

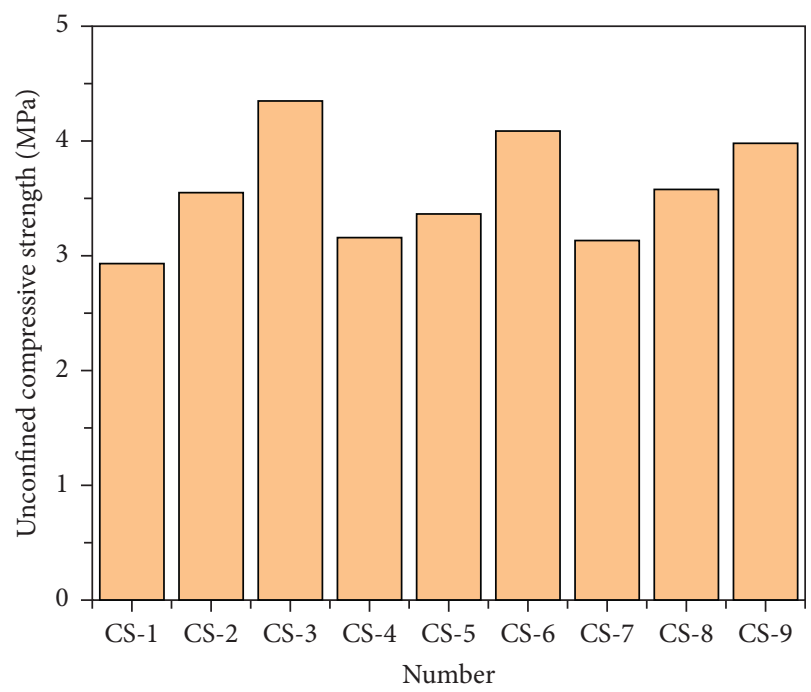

FIGURE 7: 28-day compressive strength of cement-stabilized coral sand.

the expansion agent content $\left(\mathrm{C}_{3}\right)$ is $7.9 \%$ higher than that of $\mathrm{C}_{1}$ because the expansion agent fills and refines the internal pores of the cement-stabilized coral sand to a certain extent, thereby improving the compactness and strength of the mixture. The maximum values of the indicators $K_{i j}$ in the three levels of $A, B$, and $C$ factors are $\mathrm{K}_{3 \mathrm{~A}}, \mathrm{~K}_{3 \mathrm{~B}}$, and $\mathrm{K}_{3 \mathrm{C}}$, respectively. Therefore, according to the strength evaluation, the optimal combination of cement-stabilized coral sand is $\mathrm{A}_{3} \mathrm{~B}_{3} \mathrm{C}_{3}$.

3.4. Scouring Rate. It can be seen intuitively from Figure 8 that the amount of cement-stabilized coral sand scouring tends to regulate after 30 minutes. In addition, the cumulative scouring amount of the mixture increased with the increase of the scouring time, but the growth rate gradually became slower, and the scouring rate of $8 \%$ cement was reduced by $66 \%$ compared with $5 \%$ cement. At the same time, the erosion rate of cement-stabilized coral 


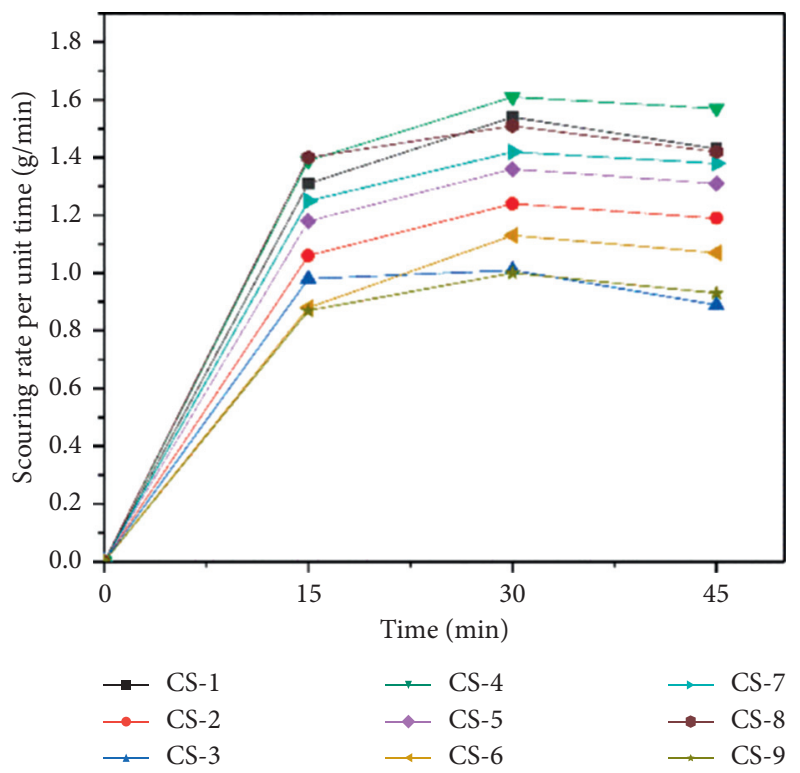

Figure 8: Scour rate over time.

sand decreased with increasing cement content. As the amount of cement increases, more hydration products will fill the internal pores of the mixture and increase the bonding strength of the particles so that the water is difficult to diffuse into the interior of the mixture, which improves the antiscouring performance of the cementstabilized sand to a certain extent. Before the scouring test, the cement-stabilized sand surface was flat (Figure 9), and after the test, the cement-stabilized sand surface had some particle loss, and the mass loss was relatively large (Figure 10). Therefore, in the actual construction process, measures should be taken to prevent rainwater from directly entering the grassroots and causing erosion damage to the roadbed. According to the orthogonal analysis results in Table 7, the optimal dosage is $\mathrm{A}_{3} \mathrm{~B}_{3} \mathrm{C}_{2}$.

In summary, considering the relationship between strength, shrinkage, and scouring, the three factors were finally selected as $A_{1}, B_{3}$, and $C_{2}$, respectively. Therefore, the ratio of cement-stabilized coral sand mixture to cement is $6 \%$, and the amount of CAS expansion agent is $8 \%$ (accounting for cement).

3.5. Comparison of Cement-Stabilized Coral Sand with Expansion Agent and Ordinary Cement-Stabilized Coral Sand. According to the orthogonal experiment, the optimal expansion agent amount for the cement-stabilized coral sand was obtained, and the comparison experiment was carried out, with $6 \%$ cement-stabilized coral sand without any expansion agent.

The dry shrinkage coefficient of the cement-stabilized coral sand obtained according to the recommended mix ratio was significantly lower than that of the unfilled expander. The expansion factor of the addition of expansion agent is $110.5 \times 10^{-7}$, which is $32.3 \%$ lower than the average dry shrinkage factor of $162.4 \times 10^{-7}$ of $6 \%$ cement without an expansion agent in Figure 11. Not only does the strength

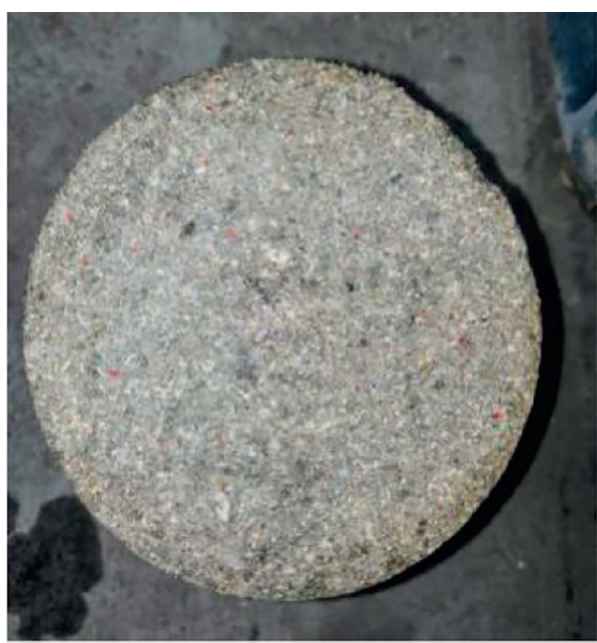

FIgURE 9: The sample before scouring.

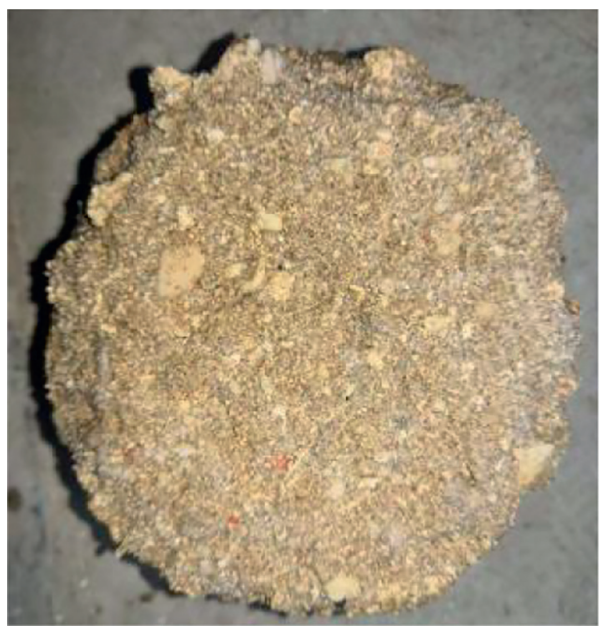

FIgURE 10: The sample after scouring.

meet the requirements of 3-5 MPa, but also the crack resistance is effective.

The scanning electron microscopy (Hitachi S-4800) analysis of cement-stabilized coral sand with CAS and ordinary cement-stabilized coral sand over a 28-day period was carried out, under the magnification of $1,000 \times-10,000 \times$, and the scanning electron micrograph is shown in Figure 12. Figure 12(a) shows the pores of coral sand everywhere to prove its porosity, while the roughness of the pore surface was well adhered to the cement. The needle-shaped C-S-H gel formed a network and ettringite to form a cement stone structure but had many internal voids (Figure 12(c)). The hydration of the expansion agent created a void in which the ettringite was filled with a portion of the cement-stabilized coral sand, resulting in an increase in density (Figure 12(b)). The cement-stabilized coral sand with an expansion agent has much greater compactness than the cement-stabilized coral sand without an expansion agent. Under the same conditions, the expansion pressure of cement-stabilized coral sand by water 


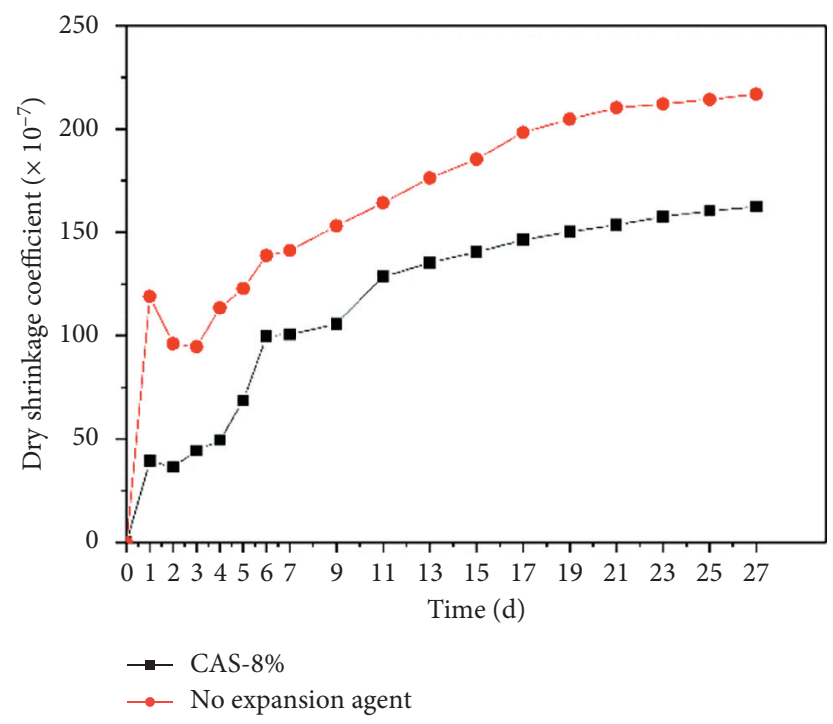

Figure 11: Comparison of dry shrinkage coefficients.

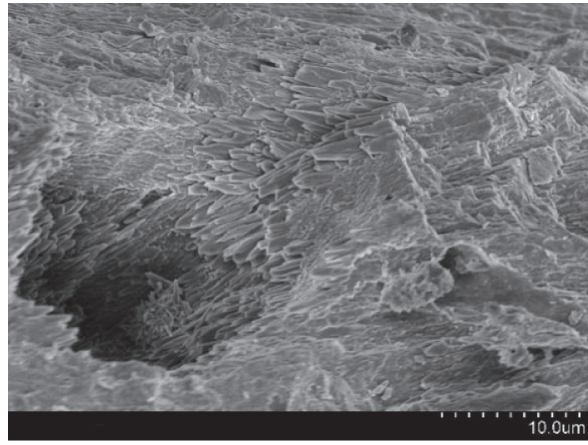

(a)

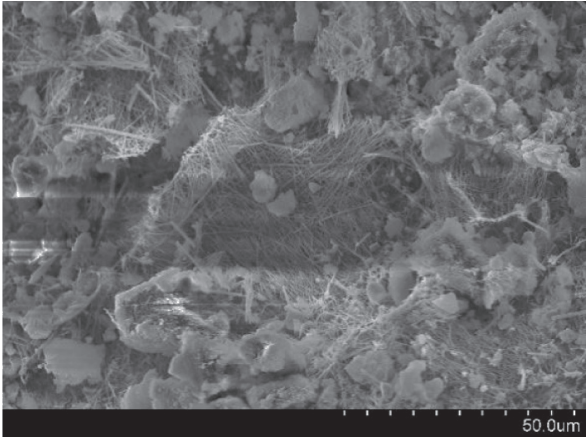

(b)

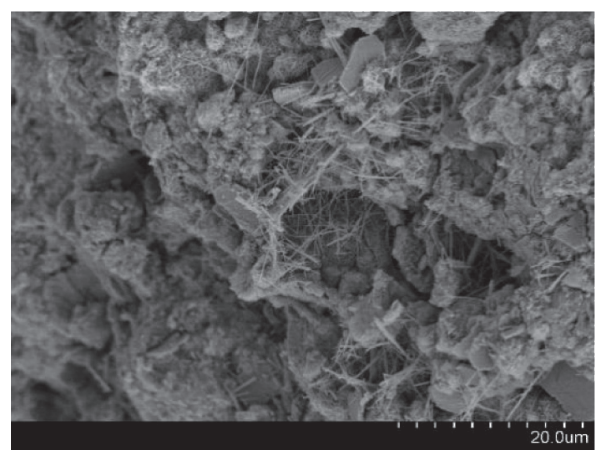

(c)

Figure 12: Microstructure analysis. (a) Internal pores of coral sand. (b) Cement-stabilized coral sand with 8\% CAS. (c) Cement-stabilized coral sand without expansion agent.

is obviously larger than that of cement filled with an expansion agent [24].

XRD (AXS D8 ADVANCE) was used to determine the composition of the reaction product by determining the specific diffraction peak of the 28-day cement-stabilized coral sand, and the diffraction angle was set to 15 to $90^{\circ}$ for testing. Because the main component of coral sand is $\mathrm{CaCO}_{3}$, it has a great influence on other diffraction peaks, so the components of coral sand are removed and analyzed for hydration products. The main hydration products are $\mathrm{Ca}$ $(\mathrm{OH})_{2}$, C-S-H, and AFt. Compared with ordinary cementstabilized coral sand in Figure 13, ettringite and $\mathrm{Ca}(\mathrm{OH})_{2}$ have larger peak diffractions and more crystal components in CAS. Therefore, the compactness of CAS cement-stabilized coral sand is better than that of ordinary cementstabilized coral sand. 


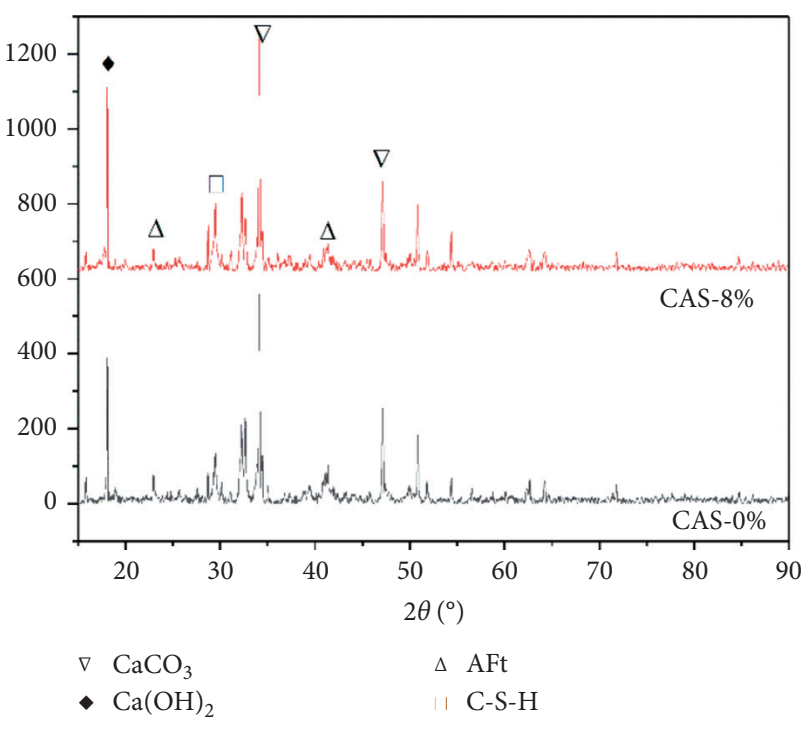

Figure 13: XRD component analysis.

\section{Conclusions}

Based on the test results obtained, the following conclusions can be drawn:

(1) The proper amount of expansion agent has an inhibitory effect on the shrinkage of cement-stabilized coral sand, but the effect of large amount is not obvious.

(2) The amount of expansion agent has a certain influence on the strength: $\mathrm{C}_{3}$ was $7.9 \%$ higher than $\mathrm{C}_{1}$, owing to the fact that the microexpansion of the expansion agent improves the compactness of the mixture, reduces internal defects, and increases the overall strength of the material.

(3) For scouring, cement content and expansion agent type are the most important factors, and their effect on scouring is more obvious than that of expansion agent content. The difference in the expansion source results in a discrepancy in the compactness of the samples.

(4) Compared with ordinary cement stabilized coral sand, the sample with an added expansion agent has a denser structure and more hydration products.

\section{Data Availability}

Some of the data required to reproduce these findings cannot be shared at this time as the data also form part of an ongoing study.

\section{Conflicts of Interest}

The authors declare that there are no conflicts of interest regarding the publication of this paper.

\section{Acknowledgments}

The authors would like to acknowledge the Fundamental Research Funds for the Central Colleges (310831173701),
National Natural Science Foundation of China (51608045), Key Research and Development Program of Shaanxi Province (2018SF-380), and College Students' Innovative Entrepreneurial Training Plan Program (201910710149), which collectively funded this project.

\section{References}

[1] M. Zi, K. Y. Liu, S. Liu et al., "Study on the basic properties of coral sand used as fine aggregate," Construction and Building Materials, vol. 5, pp. 11-14, 2015.

[2] W. F. Li, J. Guan, S. H. Ma et al., "Application of sea sand and coral reefs in the production of concrete mixed with Seawater," Concrete, vol. 5, pp. 148-152, 2016.

[3] R. J. Mi, H. F. Yu, H. Y. Ma et al., "Study on the mechanical property of coral concrete," Ocean Eng., vol. 34, no. 4, pp. 47-54, 2016.

[4] B. Martin-Garin, B. Lathuilière, E. P. Verrecchia, and J. Geister, "Use of fractal dimensions to quantify coral shape," Coral Reefs, vol. 26, no. 3, pp. 541-550, 2007.

[5] R. Schnellmann, H. Rahardjo, H. R. Schneider et al., "Unsaturated shear strength of a silty sand," Engineering Geology, vol. 162, pp. 88-96, 2013.

[6] A. Gangopadhyay, A. Sarkar, and A. Sarkar, "A study on natural coral stone-a fractal solid," Applied Physics A Processing, vol. 109, no. 4, pp. 979-983, 2012.

[7] K. R. Demars, V. A. Nacci, W. E. Kelly et al., "Carbonate content: an index property for ocean sedimentd," in Proceedings of the 8th OTC Conference, pp. 97-106, Paper PTC2627, Houston, TX, USA, May 1976.

[8] V. Bandini and M. R. Coop, "The influence of Particle breakage on the location of the critical state line of sands," Soils and Foundations, vol. 51, no. 4, pp. 591-600, 2011.

[9] W. R. Bryant, A. P. Deflache, and P. K. Trabant, "Consolidation of marine clays and carbonates," in Deep Sea Sediments, A. L. Inderbitzen, Ed., pp. 209-244, Plenum Press, New York, NY, USA, 1974.

[10] C. Liu and R. Wang, "Preliminary research on physical and mechanical properties of calcareous sand," Rock and Soil Mechanics, vol. 19, no. 1, pp. 32-37, 1998.

[11] R. A. Arumugam and K. Ramamurthy, "Study of compressive strength characteristics of coral aggregate concrete," Magazine of Concrete Research, vol. 48, no. 9, pp. 141-148, 1996.

[12] R. W. King and W. R. Van Hooydonk, "Geotechnical investigations of calcareous soils on the North West shelf," in Proceedings of the 12th Annual Offshore Technology Conference, pp. 303-314, Offshore Technology Conference, Houston, TX, USA, May 1980.

[13] S. Khaled and J. K. Raymond, "Fatigue behavior of fiberreinforced recycled aggregate base course," Journal of $\mathrm{Ma}$ terials in Civil Engineering, vol. 89, no. 5, pp. 124-130, 1999.

[14] K. P. George, "Pavement thickness design using low strength the base and subbase materials," TTR, vol. 1043, pp. 213-216, 1985.

[15] Y.-P. Sheng, H.-B. Li, and S.-F. Chen, "Mix design of semirigid base material based on anti-erosion performance," Journal of Zhengzhou University (Engineering Science), vol. 33, no. 3, pp. 19-23, 2012.

[16] V. P. Sylovanyuk, R. Y. Yukhym, N. A. Ivantyshyn, and A. E. Lisnichuk, "Prediction of the crack resistance of cement stone and fibrous concrete," Materials Science, vol. 51, no. 4, pp. 570-575, 2016.

[17] M.-L. Zeng, S.-H. Wu, B. Hu et al., "Experimental study on steel slag-crushed stone pavement base materials stabilized 
with portland cement," Natural Science Journal of Xiangtan University, vol. 33, no. 1, pp. 29-33, 2011.

[18] T.-H. Nguyen, A. Toumi, A. Turatsinze, and F. Tazi, "Restrained shrinkage cracking in steel fibre reinforced and rubberised cement-based mortars," Materials and Structures, vol. 45, no. 6, pp. 899-904, 2012.

[19] Y. Gong, J.-L. Gao, and J.-J. Ding, "Experimental research on coarse cement improving crack-resistance of RCC," Water Resources and Power, vol. 33, no. 7, pp. 135-191, 2015.

[20] Y. Y. Wu, Y. Peng, Y. D. Liu, and L. L. Jia, "Expansion of cement mortar mixing expansive agent under different curing conditions and compressive strength in constrained conditions," Applied Mechanics and Materials, vol. 405-408, pp. 2534-2537, 2013.

[21] H. Zhang, L. Li, W. Wang, and J. Liu, "Effect of temperature rising inhibitor on expansion behavior of cement paste containing expansive agent," Construction and Building Materials, vol. 199, pp. 234-243, 2019.

[22] JTG/T F20, Technical Guidelines for Construction of Highway Roadbases, Standard, Ministry of Transport of the China, Beijing, China, 2015.

[23] JTG/T E51, Test Methods of Materials Stabilized with Inorganic Binders for Highway Engineering, Standard, Ministry of Transport of the China, Beijing, China, 2009.

[24] C. Qi, Q. Gao, and R. Wang, "Effect of fibers and expansive agent on shrinkage of self-consolidating concrete under two curing schemes," Journal of Materials in Civil Engineering, vol. 31, no. 9, Article ID 04019204, 2019. 